\title{
EDUCATION MANAGEMENT AND THE IMPACT OF INNOVATION
}

\section{Lykopoulou Zacharoula ${ }^{1}$}

Received: 11.10.2020, Accepted: 29.10.2020

\begin{abstract}
This study concerns higher education in Greece, as applied today and in the forthcoming years and its aim is ternary; firstly, the study on the implementation of international innovation indicators in education, secondly the use of innovative teaching practices and finally the relationship between different organizations and its impact on innovative educational practices. The primary research contacted with the use of a questionnaire on a sample of 471 teachers all over Greece. The findings among others show that the higher the level of innovation regarding educational services, the higher also is the level of innovation on educational processes. Moreover, the higher the level of innovation regarding educational services, the higher also is the level of innovation on business organization, and the higher the level of innovation regarding educational processes, the higher also is the level of innovation on business organization. The importance of this work lies in its contribution to the description and definition of the concept, characteristics and operation of organizational innovation in the context of education, as well as the possibility of its use by the supervisors and teachers of the specific school level for better understanding and management of the culture of each school unit.
\end{abstract}

Keywords: Innovation, Management educational services, Educational process, Innovative practices

JEL Codes: I20, M10

\section{Introduction}

The term innovation appears to have various meanings which, however, share common features and characteristics. According to the Major Greek Dictionary (2006: 32), innovation is an "innovation or reform". In addition to identifying this term innovation with reform, one can find even more meaningful terms such as "best practice" "creativity" and "change". According to Cros 1996

\footnotetext{
${ }^{1}$ Kinder garden „Kalampaki“, Drama, Greece, Director. e-mail:stratoszahos@gmail.com; ORCID ID: https://orcid.org/0000-0001-5237-7895
} 
(in Sultana, 2001) there are over three hundred (300) definitions of innovation. The most common term, according to Cros (1996), defines innovation as "something new" (eg an object, idea, practice or process, etc.) either in absolute terms or under the perspective through of which it is implemented or applied. According to Sultana (2001: 5), this common term refers not to a new idea but also to its application. Marsh's views are similar (1997: 185, referring to Sultana, 2001: 5), which argues that "authentic innovations" involve an "improvement intention" and aim not at the cancellation, cancellation or sabotage of current ideas, practices or procedures applied to a system, but to improve their efficiency and to renew the stakeholders.

\section{Defining education}

The OECD definition of innovation refers to "converting an idea into a marketable product or service, a new or improved production or distribution process, or even a new method of providing social services ... emphasis is given ... both in the process and in the outcome of innovation ... the emergence of new products, methods or services can be done in all areas of activity, traditional or high-tech, public or commercial, industrial, agricultural or tertiary. Innovation may also concern services of general interest or general interest". Educational innovation refers to the introduction or integration of new elements, situations, processes or persons into the educational work to modify, improve, replace or change part or all of the educational practice. The definition of Yamazumi (2008) expresses more precisely the delineation of educational innovations. According to these writers, educational innovations relate to "real and practical interventions designed to bring about improvements in education, whether or not these improvements are realized or simply delineated by the actors involved, irrespective of whether these changes are aimed at the aims, in skills, philosophies, beliefs, behaviors or practices".

This definition is of great interest, given that specific mention is made of the interventions that are often not implemented, as is clarified in the respective chapter on innovations in our country, as well as the real ones, which are also facing, difficulties in their application. This definition is, however, quite flexible in our view because it refers to individual elements or processes of the educational fabric that are being addressed in a dissociative way (eg goals, skills, beliefs, practices, etc.) as a pursuit of educational innovation, instead of addressing the "ecology of schools" (Subramanian et al., 2016) or the culture of education (Porter et al., 2014; Bryndin, 2019). As we will say later, if educational innovation is not addressed in the overall educational structure, the educational 
improvements or changes that are being sought impinge on the existing system that resists the intended educational innovations which are aborted or fall into a vacuum. In the modern economy of knowledge, a business success is achieved by the enterprises that develop an innovative approach (Dimitrova, Sotirova, 2020). These are the enterprises in which human resources and managers are able to create conditions conductive to discovering and developing the workers' and employees' innovative potential. The process of globalization and the continuous development of the knowledge society places emphasis on education and training as important economic, social and political priorities (Rizova, Dimitrova, 2017). The development of human capital depends on many factors. One of the most important of them is access to education and vocational training and its quality (Dimitrova, Vladov, 2017). In modern society, lifelong learning is defined as a critical factor for personal development and a guarantee of a successful career, as formal education is only one part of what a person learns in life (Rizova, Dimitrova, 2017).

\section{Innovation in the teaching process and levels of educational innovation}

The term instructional innovation refers to the introduction, renewal or replacement of various factors of the didactic work and / or the teaching practices. A classic definition is that of Lee (1966, in Schoen \& Fusarelli, 2008) which refers to a "continuous one that involves major changes to an existing teaching practice as well as the introduction of new elements and procedures or a complete replacement of existing teaching practice. Continuing a teaching practice refers to the various subjects of the teaching work, such as planning and organizing teaching, new methods, models, strategies or forms of teaching, making teaching decisions, using audiovisual and other media (eg new technologies, PCs, etc.), the climate of the classroom, the management of teaching time and other activities (Hofman et al., 2013, Krasteva R., Pantelis Ef., 2017). In addition, all educational innovations are often targeted at the "instructional environment" which aims to transform, modify or change it deliberately or not deliberately, a goal that is not always achieved " (Hovne, Hovne \& Schott, 2014; Deming et al., 2015).

As mentioned above, many experts even associate the term innovation with the terms: change, renewal, best practice, creativity, or reform (Haller, Bullinger $\&$ Moslein, 2011). However, before we refer to aspects or levels of educational innovation, it is worthwhile to note the relationship between innovation and change, since the latter is often the pursuit or objective of the former. According to Porter et al. (2014), the change is characterized as "the adoption of an 
innovation that seeks to improve the effects of education by modifying or replacing the practices that apply". In the literature on educational innovation, one often finds the point that a change requires complex planning and preparation processes at various levels, particularly those directly involved in it (Thorsteinsson, 2014). For the issues, however, these are discussed in more detail in other chapters.

The curriculum is the medium in which the school's knowledge, skills, values and generally the cultural assets of a country are established and is closely linked to school textbooks, work plans, audiovisual and technological media, as well as the activities that are an integral part of it (Maritz et al., 2014). The curriculum is usually at the heart of many of the educational innovations that are being implemented internationally. The reason is that often linked to both national and local needs as well as to external changes, trends or challenges at the international stage, such as globalization, the knowledge and information society, high technology and many others. National needs and international changes or trends are putting pressure on educational systems to renew or change CPIs in which school knowledge is structured to better respond to international challenges and to competition between countries (Serpell \& Adamson-Holley, 2017). Such challenges have contributed to the creation of the new form of the Greek BS, namely, the Interdisciplinary Framework of the Program of Studies (DEPPS), the Curriculum for Advanced Studies (ASP) work plans, the Flexible Zone, as argued by various experts in our country (Al-Emran, Elsherif \& Shaalan, 2016) and abroad (Rikkerink et al., 2016).

Innovations in the curriculum have direct and indirect effects on other successive functions of the educational project. is directly related to the didactic work, which is why Borrego and Henderson (2014) argued that the curriculum is the "contraction" of the heart of education while teaching is "its expansion". Multiple interconnections of the curriculum with other aspects of the didactic work, but also the new situation created in the context of its implementation provokes several times reactions and uncertainty for the teachers. For example, when a new curriculum has been applied in Slovenia, which demanded new roles and responsibility that burdened teachers' work, teachers made a strike (Gomez, Gomez \& Gifford, 2010), as is often the case in our country as well as in other countries.

The complexity of the process of implementing educational innovations and the essential preconditions 
As will be seen from what follows in the next chapters, the process of implementing an educational innovation is not an easy process. Instead, it depends on multiple factors on multiple levels to achieve and succeed. What we mention in the section below shows that even in cases where educational innovations have been institutionalized, it is not certain that their implementation will be realized and consolidated. This is because attempting to implement educational innovation is not an isolated act, but a process with a variety of aspects or levels, as has already been mentioned. Sultana (2001) argues that the application of educational innovation is a "life cycle" that consists of a fundamental dynamic and is governed by a variety of strategies including the origin of innovation, ie who to promote it, the means by which it is channeled towards schools, the ways in which it is accepted by schools, how it is piloted, and how it is monitored and evaluated ... to succeed". In principle, the chances of a successful success of an innovation are much greater if the educational innovation sought is not "foreign" or different to the institution of the institution in which it is introduced. On the other hand, if educational innovation or reform is "genius" - that is, it comes from the institution itself or the organization - the chances increase its success (Bradshaw \& Hultquist, 2016; Bryndin, 2019). This direction could be also followed in other spheres such as hospitality and (Kyurova, Kiryakova-Dineva, 2020:4614)

A minute and important point is who and how an innovation is being promoted. There are indications that, when educational innovation is promoted from "top to bottom", there is a potential for the educational innovation sought to encounter obstacles. To a large extent, educational innovations in centralized systems, such as our country, are carried out in this way and are imposed without substantial results (Maritz et al., 2014). Educational innovation, by definition, according to Lozano et al. (2015) provokes, a priori, a process of questioning and resistance to it and is treated as a "foreign body". This motivates Sultana (2001) to argue that educational innovations should not be promoted one-dimensionally from top to bottom. When this becomes educational innovation "it challenges the dominant positions and practices and leads to further questioning by all those who have an interest in preserving the old ways, on the one hand, and those who show preference to follow the new ways from the other". In fact, and in view of the resistance put forward by the stakeholders, an educational innovation will not be adopted if its actors do not identify with it, nor are they given the appropriate incentives - for example. Wages, professional advancement, etc. - and there are no similar forms of support. This support - economic, ethical, etc. - is important for the realization of educational innovation because sometimes there is only 
apparent support without the corresponding resources or appropriate forms of delivery. In these cases Sultana (2001) considers that "educational innovation is likened to the Trojan Horse, where the hope is that it will expand and influence other elements or processes of the system or the educational web".

Given that educational innovation is identified with change, it is imminent that the persons involved who are accustomed to a given situation will not accept and resist it, since the upcoming change will disrupt the balance of dominant practice that is established in their institution. This difficulty is expressed by a number of scholars, others stressing that critical factors are "people and relationships, and the support mechanisms needed to successfully implement educational innovations, especially when seeking to improve practices" (Credaro, 2001). Similar views are expressed by other scholars, such as Lozano et al. (2015) who say that education reforms are difficult to precisely plan, but educational innovations are even more difficult to implement.

Various difficulties in the implementation of reforms or educational innovations are highlighted by Fidalgo-Blanco, Sein-Echaluce and GarcíaPenalvo (2015) who argue that their complexity is due to a variety of factors including: "Educational innovation or change must not is linear and needs to evolve through its various stages of implementation, while the requisite conditions are the commitment of the persons or bodies involved, collective decision-making, the common vision, cooperation as well as the operation of support structures". Given these peculiarities, he suggests four steps in implementing any change or educational innovation. These stages are: "first, the creation of the conditions for information and awareness of the upcoming change or innovation, second, the consolidation of the funnel-facilitation structures, the third, the complexity of the parallel process concerning the persuasion of the persons involved, the decision- and their commitment to promoting educational innovation or change, fourth, the start of implementation, and the adaptation of educational innovation to the school's context and its assessment".

According to the above, we note that non-realization of educational innovation or change is due to a number of factors, the most important of which are: attitudes or attitudes - natural or negative - of the persons involved, the lack of a holistic approach to educational innovation, change or reform, the absence of follow-up and post-evaluation, the absence of material, moral, scientific support, and the process of change that disfigures the persons involved (FidalgoBlanco, Sein-Echaluce\& García-Penalvo, 2015; Bryan \& Clegg, 2019). 


\section{Methodology}

The appropriate research method was selected based on the literature review as well as to serve the objectives of the research. This primary research is characterized as quantitative and it is conducted using a questionnaire, a tool common to similar research efforts (Ghauri, Gronhaug \& Strange, 2020). The overall aim of the research is to investigate teachers' perceptions of innovation in educational organizations. Based on the purpose of the research, the research design focused on the following research questions:

1. What are the teachers' views on innovation in educational services?

2. Is there a correlation between innovation levels at different levels of educational organizations?

3 . Is there a correlation between the relationships of the educational organization and the levels of use of innovative practices in educational organizations?

The questionnaire was selected as the research data collection tool. The selection of the questionnaire was based on the advantages it can offer in terms of research compared to other options such as interviews and focus groups. Specifically, the questionnaire was selected as it can lead to fast, accurate and as low cost as possible collection of research data (Ghauri, Gronhaug \& Strange, 2020). The questionnaire was based on previous research on innovative educational programs in Greece, with the necessary additions and improvements in terms of questions to meet all research objectives. In particular, the questionnaire includes 10 sections, with questions and sub-questions and with the measurement of which to be done with different scales. Categorical as demographics, but also 7-point Likert scales (where $1=$ None, $7=$ Extremely high) to emphasize the intensity of the choices and to be able to compare them.

In the present study, the target population is teachers in the Greek education system and the research sample was a random sample of 471 individuals. Simple random sampling was selected to collect the sample, with individuals being randomly selected from a database of the Ministry of Education, which functioned as a sampling framework. This particular sampling method has advantages and disadvantages over other ways of selecting population units. In particular, it offers random data collection as the researcher essentially randomly selects without discrimination who to ask, but instead finds it difficult to collect data quickly (Ghauri, Gronhaug \& Strange, 2020). Geographically, the survey was conducted with respondents in all regions of the country and the identification of respondents was carried out via the internet. Below is the composition of the research sample. Finally, the majority of the 
respondents were females (61.1\%), 33.8\% were from 31 to 45 years old, $91 \%$ hold a $\mathrm{PhD}$ while $47.8 \%$ of the respondents have less than 5 years of professional experience. The analysis of the data provided by the primary data analysis was performed using the SPSS 26.0 statistical analysis program. The One-way ANOVA and Pearson correlation parametric test were selected to verify statistically significant correlations at $\mathrm{a}=0.05$ level of significance.

\section{Research Findings}

Figure 1 presents the answers of respondents regarding institution's most significant innovation concerning educational services in the last three years that has most transformed the business performance. Specifically, 64\% state innovative educational packages are the most significant innovation concerning educational services in the last three years, following by offering collaborative programs (48\%), and offering mix subject programs (40\%).

Figure 1: Institution's most significant innovation concerning educational services

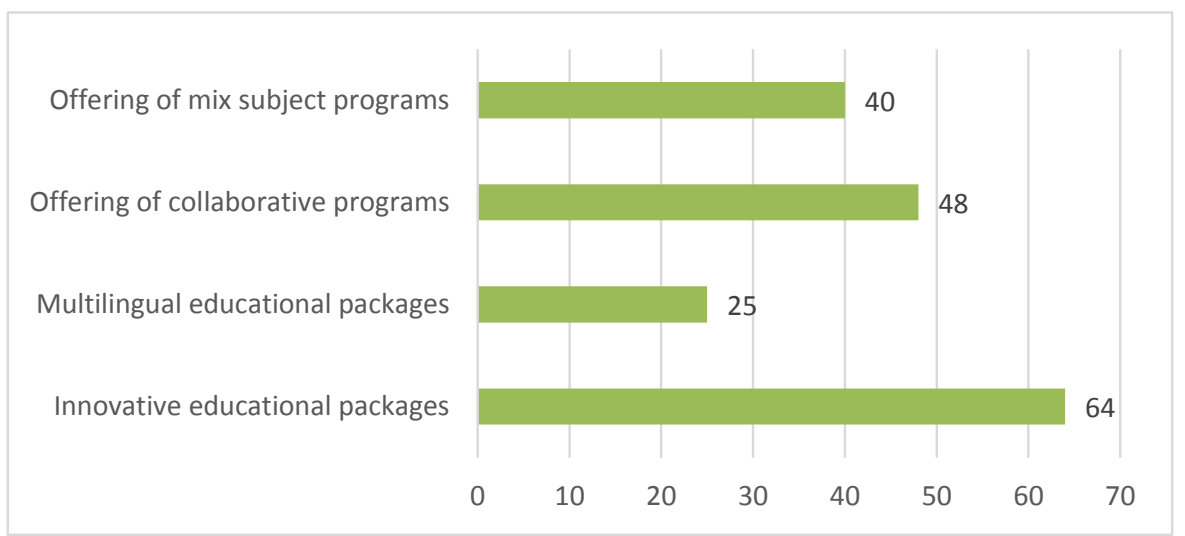

Table 1 presents the answers of respondents regarding the importance of innovative change on educational delivery processes. Specifically, the respondents state that innovative change regarding educational delivery processes is most important for new learning resources or facilities (eg. virtual environments) $(\mathrm{M}=6.04)$ following by new teaching and learning methods (eg peer group reviews) $(\mathrm{M}=5.94)$ and finally new approaches to student monitoring or support (eg measures to improve retention) $(\mathrm{M}=3.67)$. 
Table 1: Importance of innovative change

\begin{tabular}{|l|r|}
\hline \multicolumn{1}{|c|}{ Innovation categories } & \multicolumn{2}{c|}{$\begin{array}{c}\text { Degree of innovative } \\
\text { change }\end{array}$} \\
\hline New teaching and learning methods eg peer group reviews & 5.94 \\
\hline $\begin{array}{l}\text { New approaches to student monitoring or support eg } \\
\text { measures to improve retention }\end{array}$ & 3.67 \\
\hline $\begin{array}{l}\text { New learning resources or facilities eg virtual } \\
\text { environments }\end{array}$ & 6.04 \\
\hline
\end{tabular}

Table 2 presents the answers of respondents regarding institution's most significant innovation concerning educational delivery processes in the last three years, that has most transformed the business performance. Specifically, $81 \%$ state that the use of group meeting applications are the most significant innovation concerning educational delivery processes in the last three years, following by internet platforms (78\%), and the use of innovative teaching software (68\%).

Table 2: Institution's most significant innovation concerning educational delivery processes in the last three years

\begin{tabular}{|l|r|}
\hline \multicolumn{1}{|c|}{ Innovation concerning educational services } & Percentage \\
\hline Use of innovative teaching software & 68 \\
\hline Use of internet platforms & 78 \\
\hline Use of internet applications & 53 \\
\hline Use of group meeting applications & 81 \\
\hline
\end{tabular}

The majority of the respondents state regarding contrasting strategies that their institutions always test alternative innovation designs before adopting one that fits our specific circumstances $(M=6.10)$ and that innovations are adopted only after a comprehensive evaluation of our needs and a thorough evaluation of the business case $(M=5.49)$. On the contrary at lower degree the respondents state that strategic innovations are usually built around a single good idea $(\mathrm{M}=$ 2.87). 
Table 3: Contrasting strategies

\begin{tabular}{|c|c|c|}
\hline & $\begin{array}{l}\text { Mean } \\
1 \leftrightarrow 7\end{array}$ & \\
\hline $\begin{array}{l}\text { Innovations are always adopted } \\
\text { when they have become standard } \\
\text { practice in our sector. }\end{array}$ & 5.49 & $\begin{array}{l}\text { Innovations are adopted only } \\
\text { after a comprehensive evaluation } \\
\text { of our needs and a thorough } \\
\text { evaluation of the business case }\end{array}$ \\
\hline $\begin{array}{l}\text { We only implement the } \\
\text { commonly accepted standard } \\
\text { form of innovations. }\end{array}$ & 6.10 & $\begin{array}{l}\text { We always test alternative } \\
\text { innovation designs before } \\
\text { adopting one that fits our } \\
\text { specific circumstances }\end{array}$ \\
\hline $\begin{array}{l}\text { Strategic innovations are usually } \\
\text { built around a single good idea }\end{array}$ & 2.87 & $\begin{array}{l}\text { Strategic innovations usually } \\
\text { emerge from the juxtaposition of } \\
\text { several separate ideas }\end{array}$ \\
\hline
\end{tabular}

The findings show that the higher the level of innovation regarding educational services, the higher also is the level of innovation on educational processes $(\mathrm{r}=.890, \mathrm{p}<0.01)$. Moreover, the higher the level of innovation regarding educational services, the higher also is the level of innovation on business organization, and the higher the level of innovation regarding educational processes, the higher also is the level of innovation on business organization $(\mathrm{r}=.559, \mathrm{p}<0.01)$. Moreover, the findings show that the higher the level of innovation regarding educational services, the higher also is the level of relationship with educational service providers and the level of relationship with government agencies. The level of innovation on educational processes presents a positive statistically significant relationship with the level of relationship with educational service providers $(\mathrm{r}=.393, \mathrm{p}<0.05)$ and the level of relationship with government agencies $(\mathrm{r}=.326, \mathrm{p}<0.01)$. Therefore, the higher the level of innovation regarding educational processes, the higher also is the level of relationship with educational service providers and the level of relationship with government agencies. Finally, the level of innovation on business organization presents a positive statistically significant relationship with the level of relationship with educational service providers $(r=.382, p<0.05)$ and the level of relationship with government agencies $(r=.344, p<0.01)$. Therefore, the higher the level of innovation regarding the business organization, the higher also is the level of relationship with educational service providers and the level of relationship with government agencies. 
Table 4: Correlations

\begin{tabular}{|c|c|c|c|c|c|c|}
\hline & 1 & 2 & 3 & 4 & 5 & 6 \\
\hline $\begin{array}{l}\text { 1. Level of innovation on educational } \\
\text { services }\end{array}$ & 1 & $.890^{* *}$ & $.559^{* *}$ & $.393^{*}$ & $.326^{*}$ & .016 \\
\hline $\begin{array}{l}\text { 2. Level of innovation on educational } \\
\text { processes }\end{array}$ & & 1 & $.572^{* *}$ & $.382^{*}$ & $.344^{*}$ & .033 \\
\hline $\begin{array}{l}\text { 3. Level of innovation on business } \\
\text { organization }\end{array}$ & & & 1 & $.356^{*}$ & $.387^{*}$ & .062 \\
\hline $\begin{array}{l}\text { 4. Relationships with educational } \\
\text { service providers }\end{array}$ & & & & 1 & $.335^{*}$ & .054 \\
\hline $\begin{array}{l}\text { 5. Relationships with government } \\
\text { agencies }\end{array}$ & & & & & 1 & $.801^{* *}$ \\
\hline $\begin{array}{l}\text { 6. Relationships with professional } \\
\text { networks }\end{array}$ & & & & & & 1 \\
\hline
\end{tabular}

**. Correlation is significant at the 0.01 level (2-tailed).

*. Correlation is significant at the 0.05 level (2-tailed).

\section{Conclusion}

The importance of this work lies in its contribution to the description and definition of the concept, characteristics and operation of organizational innovation in the context of education, as well as the possibility of its use by the supervisors and teachers of the specific school level for better understanding and management of the culture of each school unit. Introducing and implementing innovations in the school unit is a necessary process in order to solve problems, improve its results and adapt to the changing social environment. This process is not automatic with a predetermined result, and the degree of its success depends on several factors. The principal as a leader and not just as an administrator, is the one who must take the appropriate steps so that the school unit can select, introduce and implement innovations successfully.

In a constantly changing economic, social and technological environment, the introduction and use of technological innovations is considered a basic prerequisite for educational management to meet the upgraded and constantly updated goals set by the state. The purpose of our research is to determine whether and to what extent these technological innovations, such as electronic communication, remote electronic training, etc. on the one hand, they make the work of an education directorate effective and on the other hand, they facilitate teachers in their official capacity, but also the principals of the school units in their administrative work. From the results, a very positive attitude of the subjects regarding the implementation of the specific innovations is recorded. In particular, there is an improvement in the immediacy and completeness of the 
information, in the reduction of bureaucracy, costs and processing time, a clear improvement in both the better performance of teachers' duties and the general administrative and educational work, while achieving substantial and efficient diffusion. Practices but also the work of school units. In conclusion, it turns out that the project of introducing and implementing technological innovations upgrades the role and work of regional structures of education.

According to the reports, organizational innovation is a central element of an educational organization, providing members with a common meaning system that distinguishes each organization from another and influences the attitudes and behaviors of members. It acts as a factor of cohesion and stability of the body, but it can also be a brake on its effectiveness, especially when it is strong. It is created as a result of successful treatment of situations that arise in the internal and external environment, is considered valid by the members of the organization and is an object of learning for new entrants during the process of their professional socialization, which plays a very important role in its maintenance.

\section{REFERENCES}

Al-Emran, M., Elsherif, H. M., \& Shaalan, K. (2016). Investigating attitudes towards the use of mobile learning in higher education. Computers in Human Behavior, 56, 93-102.

Borrego, M., \& Henderson, C. (2014). Increasing the use of evidence-based teaching in STEM higher education: A comparison of eight change strategies. Journal of Engineering Education, 103(2), 220-252.

Bradshaw, M., \& Hultquist, B. L. (2016). Innovative teaching strategies in nursing and related health professions. Jones \& Bartlett Learning.

Bryan, C., \& Clegg, K. (Eds.). (2019). Innovative Assessment in Higher Education: A Handbook for Academic Practitioners. Routledge.

Bryndin, E. (2019). Creative Innovative Higher Education of Researchers with Flexible Skills and Synergy of Cooperation. Contemporary Research in Education and English Language Teaching, 1(1), 1-6.

Deming, D. J., Goldin, C., Katz, L. F., \& Yuchtman, N. (2015). Can online learning bend the higher education cost curve?. American Economic Review, 105(5), 496-501.

Dimitrova, R., Vladov, R. (2017). Continuing vocational training of specialists employed in the IT-sector in Bulgaria. Economics and Management, Volume: XIII, Issue: 2, Year: 2017, c. 185-207, ISSN (print): 1312-594X, ISSN (online): 2367-7600

Dimitrova, R., Sotirova, A. Human resource management within the context of innovational development of the enterprise. In: Management - Tourism - 
Culture, Studies and Reflections on Tourism Management, Ignatianum University Press, Kraków, 2020, pp 161-174, ISBN 978-83-7614-468-9

Fidalgo-Blanco, A., Sein-Echaluce, M. L., \& García-Penalvo, F. (2015). Epistemological and ontological spirals: From individual experience in educational innovation to the organisational knowledge in the university sector. Program, 49(3), 266-288.

Ghauri, P., Grønhaug, K., \& Strange, R. (2020). Research methods in business studies. Cambridge University Press.

Gomez, K., Gomez, K., \& Gifford, B. R. (2010). Educational innovation with technology: A new look at scale and opportunity to learn. Transforming America's education through innovation and technology, 7.

Haller, J. B., Bullinger, A. C., \& Moslein, K. M. (2011). Innovation contests. Business \& Information Systems Engineering, 3(2), 103-106.

Hofman, R. H., de Boom, J., Meeuwisse, M., \& Hofman, W. A. (2013). Educational innovation, quality, and effects: An exploration of innovations and their effects in secondary education. Educational Policy, 27(6), 843866.

Hovne, A. S., Hovne, B. S., \& Schott, T. (2014). Entrepreneurs' innovation benefitting from their education and training and from national policy and culture: A global study. International Journal of Entrepreneurship and Small Business, 23(1-2), 127-144.

Krasteva R., Pantelis Ef. (2017) Bridging relationships between education, refugee crisis and tourism, paper in Scientific Conference "Education and New Learning Technologies", 3-5 July 2017, Barcelona, https://library.iated.org/view/KRASTEVA2017BRI

Kyurova, V., Kiryakova-Dineva, T. (2020). Product Innovations in the Bulgarian Hospitality: Linking Theory and Practice. International Journal of Recent Technology and Engineering (IJRTE, Vol. 8 (5), 4614-4618. DOI:10.35940/ijrte.E6957.018520

Lozano, R., Ceulemans, K., Alonso-Almeida, M., Huisingh, D., Lozano, F. J., Waas, T., ... \&Hugé, J. (2015). A review of commitment and implementation of sustainable development in higher education: results from a worldwide survey. Journal of Cleaner Production, 108, 1-18.

Maritz, A., De Waal, A., Buse, S., Herstatt, C., Lassen, A., \& Maclachlan, R. (2014). Innovation education programs: toward a conceptual framework. European Journal of Innovation Management, 17(2), 166-182.

Porter, W. W., Graham, C. R., Spring, K. A., \& Welch, K. R. (2014). Blended learning in higher education: Institutional adoption and implementation. Computers \& Education, 75, 185-195.

Rikkerink, M., Verbeeten, H., Simons, R. J., \& Ritzen, H. (2016). A new model of educational innovation: Exploring the nexus of organizational learning, 
distributed leadership, and digital technologies. Journal of Educational Change, 17(2), 223-249.

Rizova, E., Dimitrova, R. (2017). State and trends in the development of continuing vocational training. Economics and Management, Volume: XIII, Issue: 2, Year: 2017, pp. 165-184, ISSN (print): 1312-594X, ISSN (online): 2367-7600

Rizova, E., Dimitrova, R. (2017). Social partnership in the field of continuing vocational training. Management and Sustainable Development, 3/2017 (64), pp. 12-16, ISSN 1311-4506 (print)

Schoen, L., \& Fusarelli, L. D. (2008). Innovation, NCLB, and the fear factor: The challenge of leading 21st-century schools in an era of accountability. Educational Policy, 22(1), 181-203.

Serpell, R., \& Adamson-Holley, D. (2017). African Socialization Values and Nonformal Educational Practices: Child Development, Parental Beliefs, and Educational Innovation in Rural Zambia. Laboring and Learning, 19-43.

Subramanian, A. M., Choi, Y. R., Lee, S. H., \& Hang, C. C. (2016). Linking technological and educational level diversities to innovation performance. The Journal of Technology Transfer, 41(2), 182-204.

Thorsteinsson, G. (2014). Innovation education to improve social responsibility through general education. Tiltai, 61(4), 71-78.

Yamazumi, K. (2008). A hybrid activity system as educational innovation. Journal of Educational change, 9(4), 365-373. 